\title{
Equivalent midterm outcomes after off-pump and on-pump coronary surgery
}

\author{
Joseph F. Sabik, MDa \\ Eugene H. Blackstone, MD ${ }^{a, b}$ \\ Bruce W. Lytle, MDa \\ Penny L. Houghtaling, $\mathrm{MS}^{\mathrm{b}}$ \\ A. Marc Gillinov, $M D^{a}$ \\ Delos M. Cosgrove, MD
}

From the Departments of Thoracic and Cardiovascular Surgery ${ }^{\mathrm{a}}$ and Biostatistics and Epidemiology, ${ }^{\mathrm{b}}$ The Cleveland Clinic Foundation, Cleveland, Ohio

Read at the Twenty-eighth Annual Meeting of The Western Thoracic Surgical Association, Carlsbad, Calif, June 18-21, 2003.

Received for publication June 17, 2003; revisions requested Aug 8, 2003; accepted for publication Aug 13, 2003.

Address for reprints: Joseph F. Sabik, MD, Department of Thoracic and Cardiovascular Surgery, The Cleveland Clinic Foundation/Desk F24, 9500 Euclid Avenue, Cleveland, OH 44195 (E-mail: sabikj@ccf.org).

J Thorac Cardiovasc Surg 2004;127:142-8

$0022-5223 / \$ 30.00$

Copyright (C) 2004 by The American Association for Thoracic Surgery

doi:10.1016/j.jtcvs.2003.08.046
Objective: Multiple reports demonstrate that off-pump surgery reduces the early morbidity associated with coronary artery bypass grafting. To determine if there are any differences in later outcomes, we compared midterm results of propensitymatched patients who underwent off- and on-pump coronary artery bypass grafting.

Methods: From January 1997 to July 2000, 481 patients underwent off-pump coronary artery bypass grafting and 3231 underwent on-pump coronary artery bypass grafting. Propensity matching was used to match 406 patients from each group. Previously, the propensity-matched off-pump patients were found to have had significantly fewer bypass grafts. These 812 patients were followed for timerelated events, including death, myocardial infarction, percutaneous coronary intervention, coronary reoperation, and the combined end point of all-cause mortality, myocardial infarction, and all coronary reintervention. Follow-up was $95 \%$ complete.

Results: At 4 years, survival was $87.5 \%$ after off-pump and $91.2 \%$ after on-pump coronary artery bypass grafting $(P=.2)$; freedom from myocardial infarction was 92.6\% and $95.7 \%(P=.7)$, respectively; freedom from percutaneous coronary intervention was $94.3 \%$ and $95.5 \%(P=.9)$, respectively; freedom from coronary reoperation was $98.1 \%$ and $99.0 \%(P=.4)$, respectively; and freedom from the combined end point of all-cause mortality, myocardial infarction, and coronary reintervention was $75.2 \%$ and $82.9 \%(P=.14)$, respectively.

Conclusions: Off-pump and on-pump coronary artery bypass grafting results in equivalent midterm outcomes. Fewer bypass grafts in the off-pump patients did not decrease survival or increase ischemic events at 4 years.

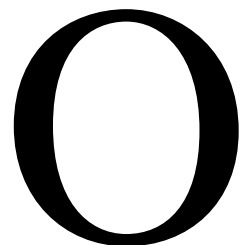

ff-pump coronary artery bypass grafting $(\mathrm{CABG})$ decreases the hospital risk of myocardial revascularization. ${ }^{1-10}$ However, the long-term effectiveness of off-pump surgery is unknown, and a few reports have suggested it may be less durable than on-pump revascularization. Fewer bypass grafts, more incomplete revascularization, increased recurrence of angina, and increased coronary reintervention have been described in patients who underwent off-pump rather than on-pump surgery. ${ }^{1,11,12}$ To determine the midterm effectiveness of off-pump surgery, we compared 4-year outcomes of propensity-matched patients who underwent either off-pump or on-pump CABG.

\section{Patients and Methods}

Patients

Using our computerized Cardiovascular Information Registry, we identified 3712 patients, along with their preoperative, operative, and postoperative variables, who underwent isolated 
CABG via a median sternotomy at The Cleveland Clinic Foundation from January 1997 to July 2000. Use of this database for research was approved by Clinic's Institutional Review Board.

At the discretion of the surgeon, myocardial revascularization was performed off-pump in 481 patients and on-pump in 3231 . Our technique of on- and off-pump surgery has been previously described. ${ }^{1}$ On- and off-pump patients were contemporaneous and not sequential groups. Patients who were converted from off-pump to on-pump $(\mathrm{n}=15)$ were included in the off-pump group.

To reduce the influence of selection bias on the comparison of outcome, patients were selected for this study using propensity score pair-wise matching of off-pump to on-pump patients. Our method has been described previously. ${ }^{1}$ Using this technique, 406 off-pump patients were matched to 406 on-pump patients. These 812 patients make up the study group. Preoperative characteristics, including extent and distribution of coronary artery disease and left ventricular function, were well matched in the two groups (Table 1). However, off-pump patients had more peripheral vascular disease and history of stroke and were somewhat less symptomatic. These were the only dissimilar preoperative characteristics $(P<.05)$ among 70 examined.

Hospital outcomes of these 812 propensity-matched patients have been previously reported. ${ }^{1}$ Briefly, the procedures performed differed in the on-pump and off-pump groups. On-pump patients received more bypass grafts than off-pump patients $(3.5 \pm 1.1 \mathrm{vs}$. $2.8 \pm 1.0, P<.001)$. This was due to fewer bypass grafts to the circumflex and right coronary artery systems in the off-pump group. Incomplete revascularization-defined as failure to graft a coronary artery system with a $50 \%$ or greater stenosis or lack of grafts to both the left anterior descending (LAD) and circumflex coronary artery systems with a $50 \%$ or greater left main coronary artery stenosis-was higher in off-pump patients (18\% vs. $31 \%$, $P<.001)$. Arterial grafts were used in a higher proportion of the distal anastomoses in off-pump patients. Left internal thoracic artery grafting was similar (91\% vs. 94\%, $P=.1$ ); however, the off-pump group had less right internal thoracic artery $(20 \%$ vs. $12 \%, P=.001)$ and saphenous vein bypass grafting $(79 \%$ vs. $67 \%, P<.001)$ and more radial artery bypass grafting ( $36 \%$ vs. $47 \%, P=.001)$.

Hospital death $(1.0 \%$ vs. $0.5 \%, P=.7)$, stroke $(1.2 \%$ vs. $0.7 \%$, $P=.7)$, and myocardial infarction $(1.2 \%$ vs. $0.7 \%, P=.7)$ were similar in the on- and off-pump patients. However, off-pump patients experienced less encephalopathy $(1.7 \%$ vs. $0 \%, P=.02)$, renal failure requiring dialysis $(1.5 \%$ vs. $0 \%, P=.03)$, red blood cell usage (53\% vs. $42 \%, P=.002)$, and fewer sternal wound infections ( $2.0 \%$ vs. $0.2 \%, P=.04)$.

\section{Follow-up}

Of the 812 propensity-matched patients, there were 806 hospital survivors. They were followed up by mail and/or telephone interview. Follow-up was $95 \%$ complete. Median follow-up of all hospital survivors was 3.2 years (mean $2.9 \pm 1.6$ years) with a range of 1 week to 5.7 years. For patients who underwent on-pump surgery, median follow-up was 3.8 years (mean $3.4 \pm 1.8$ years) with a range of 1 week to 5.7 years, and for patients who underwent off-pump surgery, median follow-up was 2.6 years (mean 2.4 \pm 1.3 years) with a range of 1 week to 5.3 years.
Table 1. Comparison of patient characteristics in propensity-matched pairs

\begin{tabular}{|c|c|c|c|}
\hline Characteristics & $\begin{array}{c}\text { On-pump } \\
n=406\end{array}$ & $\begin{array}{c}\text { Off-pump } \\
n=406\end{array}$ & $\boldsymbol{P}$ \\
\hline \multicolumn{4}{|l|}{ Demography } \\
\hline Age (mean \pm SD) & $66 \pm 11.3$ & $66 \pm 11$ & $.9 *$ \\
\hline Men & $284(70) \dagger$ & $280(69)$ & .8 \\
\hline \multicolumn{4}{|l|}{ Noncardiac } \\
\hline \multicolumn{4}{|l|}{ Diabetes } \\
\hline Insulin-treated & $35(8.6)$ & $44(11)$ & .3 \\
\hline Oral hypoglycemics & $80(20)$ & $76(19)$ & .7 \\
\hline Previous stroke & $23(5.7)$ & $38(9.4)$ & .05 \\
\hline Carotid disease & $79(19)$ & $88(22)$ & .4 \\
\hline Peripheral vascular disease & 50 (12) & 74 (18) & .02 \\
\hline Smoking history & $258(64)$ & $162(65)$ & .7 \\
\hline $\begin{array}{l}\text { Chronic obstructive } \\
\text { pulmonary disease }\end{array}$ & 78 (19) & $60(21)$ & .5 \\
\hline Hypertension & $295(73)$ & $300(74)$ & .7 \\
\hline Renal disease & $10(2.5)$ & $4(1.0)$ & .1 \\
\hline NYHA class & & & .03 \\
\hline I & $29(7.2)$ & $28(9.9)$ & \\
\hline II & $201(50)$ & $144(51)$ & \\
\hline III & $62(15)$ & $61(21)$ & \\
\hline IV & $111(28)$ & $51(18)$ & \\
\hline Not recorded & 3 & 122 & \\
\hline Left ventricular dysfunction & & & .6 \\
\hline Normal/none & $252(62)$ & $245(63)$ & \\
\hline Mild & $81(20)$ & 77 (20) & \\
\hline Moderate & $38(9.4)$ & $43(11)$ & \\
\hline Severe & $33(8.2)$ & $24(6.2)$ & \\
\hline Not recorded & 2 & 17 & \\
\hline $\begin{array}{l}\text { History of myocardial } \\
\text { infarction }\end{array}$ & $203(50)$ & $205(50)$ & .9 \\
\hline \multicolumn{4}{|l|}{$\begin{array}{l}\text { Coronary artery disease } \\
\qquad(\geq 50 \%)\end{array}$} \\
\hline Left main & $93(23)$ & $91(22)$ & .9 \\
\hline LAD & $366(90)$ & $373(92)$ & .4 \\
\hline LCX & $289(71)$ & $279(69)$ & .5 \\
\hline RCA & $315(78)$ & $315(78)$ & 1.0 \\
\hline Number of diseased systems $\ddagger$ & & & .5 \\
\hline 0 & $1(0.2) \S$ & $0(0)$ & \\
\hline 1 & $34(8.4)$ & $42(10)$ & \\
\hline 2 & $119(29)$ & $124(31)$ & \\
\hline 3 & $252(62)$ & $240(59)$ & \\
\hline
\end{tabular}

$S D$, Standard deviation; $L A D$, left anterior descending coronary artery system; $L C X$, left circumflex coronary artery system; $R C A$, right coronary artery system.

*Wilcoxon rank-sum test.

†Presented as number (percent of column total).

$\ddagger$ Defined as $\geq 50 \%$ lesion in the coronary system; left main disease is defined by itself and is not coded as 2-system disease.

$\S$ In one, $40 \%$ left main disease and $30 \%$ LAD disease.

\section{Statistical Analyses}

Descriptive summaries are presented as frequencies and percentages for categorical data, and as means and standard deviations for continuous variables. Unless otherwise specified, group comparisons were made using chi-square tests.

Time-related outcome events used to compare off-pump with on-pump CABG were (1) death from any cause, including hospital 


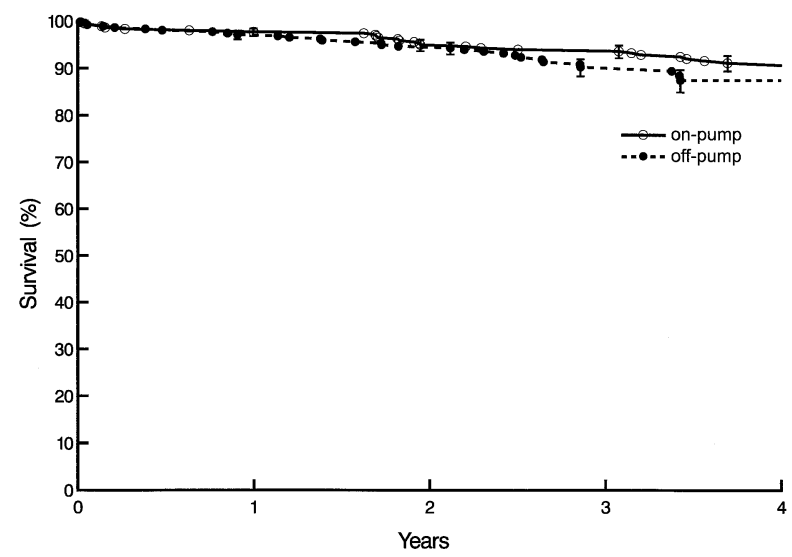

Figure 1. Survival after off-pump and on-pump coronary surgery $(P=.2)$. Each symbol represents an event positioned according to the Kaplan-Meier estimator. Vertical bars are asymmetric $68 \%$ confidence limits for these estimates. Number of patients remaining at risk at 1, 2, 3, and 4 years was $322,306,151$, and 21 in the off-pump group and $325,311,276$, and 174 in the on-pump group, respectively.

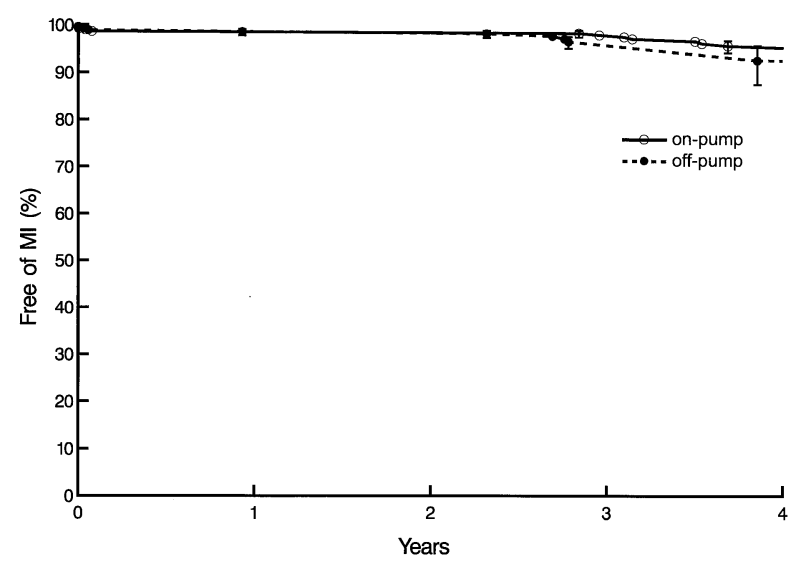

Figure 2. Freedom from myocardial infarction after off-pump and on-pump coronary artery bypass grafting $(P=.7)$. Format is as in Figure 1. MI, Myocardial infarction.

death, (2) myocardial infarction, (3) percutaneous coronary intervention, (4) coronary reoperation, and (5) the combined end point of all-cause mortality, myocardial infarction, and all coronary reintervention, defined as percutaneous coronary intervention and coronary reoperation. Time-related estimates were generated using the Kaplan-Meier method and comparisons made using the logrank statistic. Numbers of patients at risk at 1, 2, 3, and 4 years were $322,306,151$, and 21 in the off-pump group and 325,311 , 276 , and 174 in the on-pump group, respectively.

\section{Results}

Survival

Survival was similar for the on-pump and off-pump patients (Figure 1). One-, two-, and four-year survivals were $97.7 \%$,

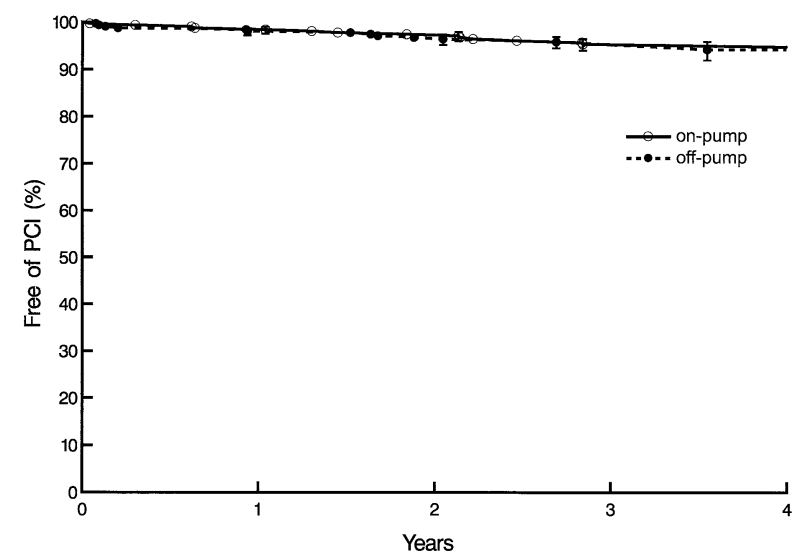

Figure 3. Freedom from percutaneous coronary intervention after off-pump and on-pump coronary artery bypass grafting $(P=.9)$. Format is as in Figure 1. PCl, Percutaneous coronary intervention.

$94.9 \%$, and $91.2 \%$ for the on-pump group and $97.1 \%$, $94.4 \%$, and $87.5 \%$ for the off-pump group, respectively $(P=.2)$.

\section{Myocardial Infarction}

Occurrence of myocardial infarction was similar in patients who underwent on- and off-pump revascularization (Figure 2). One-, two-, and four-year freedoms from myocardial infarction were $98.6 \%, 98.6 \%$, and $95.7 \%$ for the on-pump group and $98.6 \%, 98.6 \%$, and $92.6 \%$ for the off-pump group, respectively $(P=.7)$.

\section{Coronary Reintervention}

Freedom from percutaneous coronary intervention and coronary reoperation was similar in patients who underwent on- and off-pump CABG (Figures 3 and 4). One-, two-, and four-year freedoms from percutaneous coronary intervention were $98.7 \%, 97.5 \%$, and $95.5 \%$ for the on-pump group and $98.1 \%, 96.8 \%$, and $94.3 \%$ for the off-pump group $(P=$ .9). Respective freedoms from coronary reoperation were $99.4 \%, 99.4 \%$, and $99.0 \%$ in the on-pump patients and $99.4 \%, 99.0 \%$, and $98.1 \%$ in the off-pump group $(P=.4)$.

\section{Mortality, Myocardial Infarction, and All Coronary \\ Reintervention}

Freedoms from the combined end point of all-cause mortality, myocardial infarction, and coronary reintervention were $95.0 \%, 91.0 \%$, and $82.9 \%$ in the on-pump patients and $93.5 \%, 89.5 \%$, and $75.2 \%$ in the off-pump patients $(P=$ .14) (Figure 5).

\section{Discussion}

\section{Principal Findings}

In propensity-matched patients undergoing off-pump and on-pump primary $\mathrm{CABG}$, midterm survival and freedom 
from myocardial infarction, percutaneous coronary intervention, coronary reoperation, and the combined end point of all-cause mortality, myocardial infarction, and all coronary reintervention were similar.

Although much has been published on the hospital results of patients undergoing off-pump CABG, little has been reported on late outcomes. Gundry and colleagues first reported late results of off-pump myocardial revascularization, comparing 7-year outcomes of 219 unmatched offpump and on-pump patients. ${ }^{11}$ They found that the groups had similar survival. However, there was a threefold increase in need for coronary reintervention in the off-pump patients. A total of $30 \%$ of the off-pump patients underwent catheterization for recurrent symptoms and 20\% had either repeat coronary surgery or percutaneous intervention, whereas only $16 \%$ of the on-pump patients underwent angiography for symptoms and $7 \%$ had repeat coronary surgery or percutaneous intervention.

Like Gundry, we found similar late survival in the offpump and on-pump surgery patients. However, we did not identify more coronary reinterventions in the off-pump group. This difference may be due to the Gundry study being performed prior to the invention and adoption of the technology of coronary artery stabilization and exposure that has facilitated off-pump coronary revascularization. Supporting this assumption is the fact that in their off-pump patients, the majority of percutaneous interventions were performed on coronary arteries that had been previously bypassed. If effective devices for coronary artery stabilization had been available, many of these procedures may not have been necessary. The beneficial effect of coronary artery stabilization in off-pump surgery on bypass graft patency has been clearly demonstrated. ${ }^{13}$

In more contemporary studies, Beating Heart Against Cardioplegic Arrest Study (BHACAS) 1 and 2, Angelini and colleagues reported similar midterm outcomes in patients randomized to either off-pump or on-pump CABG. ${ }^{10}$ At $29.3 \pm 7.4$ months and $15.7 \pm 5.5$ months for BHACAS 1 and 2, respectively, there were no differences in mortality, cardiac-related events, or need for further coronary reintervention in the two groups. Although these patients have not been followed as long as ours, the findings are similar.

Surprisingly in our study, despite more incomplete revascularization in the off-pump patients, this group did not experience more late ischemia-related events than patients in the on-pump group. In previous studies, incomplete revascularization has been found to be associated with worse outcomes. ${ }^{14-16}$ In a recent report, Arom and colleagues found more recurrence of angina and repeat coronary interventions at 1 year in patients who underwent off-pump CABG than in those who had surgery with the assistance of cardiopulmonary bypass. ${ }^{12}$ Although they did not report

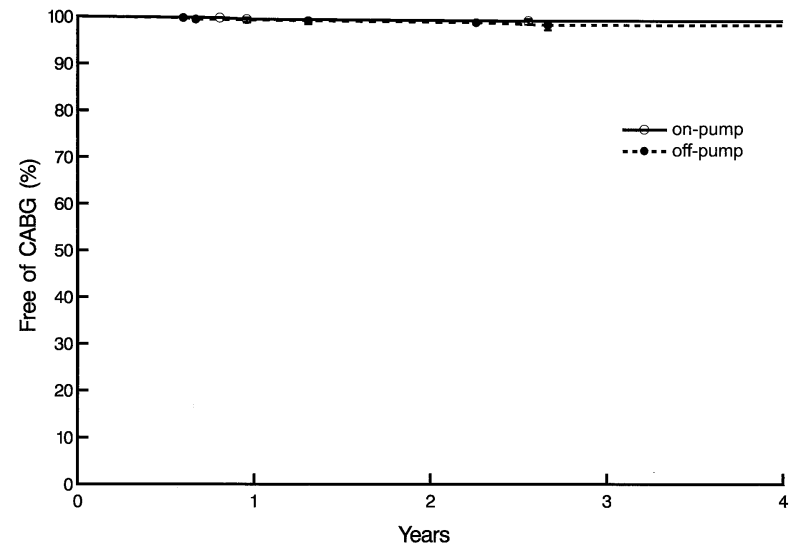

Figure 4. Freedom from redo coronary artery bypass grafting (CABG) after off-pump and on-pump CABG $(P=.4)$. Format is as in Figure 1.

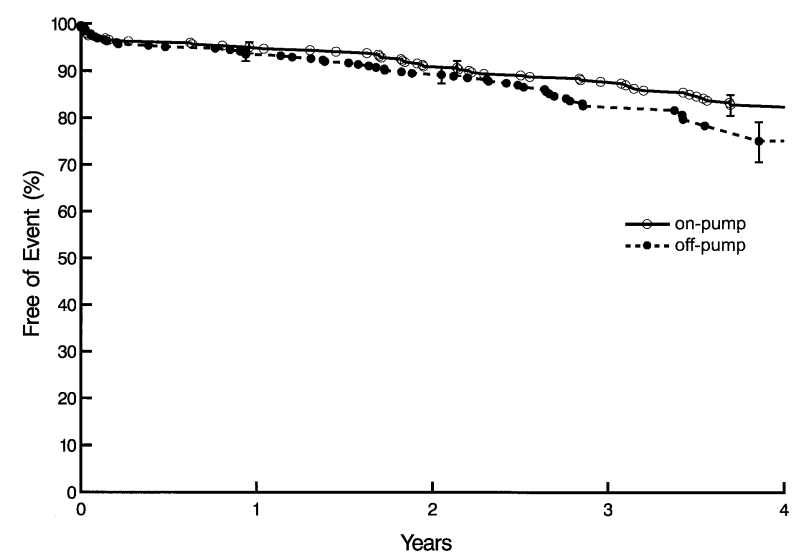

Figure 5. Freedom from death, myocardial infarction, and all coronary reintervention (coronary artery bypass grafting or percutaneous coronary intervention) after off-pump and on-pump CABG $(P=$.14). Format is as in Figure 1.

completeness of revascularization, their off-pump patients received fewer bypass grafts than their on-pump patients. ${ }^{12}$

Although there may be several reasons why incomplete revascularization did not affect late outcomes in this study, we believe two are likely possibilities. The first may be how we defined incomplete revascularization. Incomplete revascularization was not defined as the difference between what the surgeon intended to graft prior to starting the operation and what was actually done; rather, it was defined as lack of grafting any coronary artery system with $50 \%$ or more stenosis or failure to graft both the LAD and circumflex systems for $50 \%$ or more left main trunk disease. ${ }^{1}$ To determine why patients were incompletely revascularized, operative notes were carefully reviewed. When we were able to determine the reason for incomplete revascularization, patients were distributed similarly in the on- and off- 
pump groups. However, there were many more patients in the off-pump group for whom no reason for incomplete revascularization was given in the operative notes. This suggests that the surgeon did not intend to graft this area and thus believed grafting this area of the myocardium to be unnecessary. Second, detrimental effects of incomplete revascularization increase with time, and patients in this study may not have been followed long enough for differences to emerge. ${ }^{16}$

\section{Limitations}

This study was a clinical review of patients who underwent off-pump and on-pump primary CABG. Patients were not randomly assigned to either group, but instead the choice of procedure was made by the surgeon at the time of operation. Therefore, selection bias may affect our findings. To reduce the effect of selection bias on outcomes, we used propensity matching to identify well-matched off-pump and on-pump patients for comparison. In fact, the off-pump and on-pump groups were well matched in 67 of 70 evaluated preoperative characteristics.

\section{Summary}

Off-pump and on-pump CABG result in similar midterm survival and freedom from myocardial infarction, percutaneous coronary intervention, coronary reoperation, and combined all-cause mortality, myocardial infarction, and all coronary reintervention.

\section{References}

1. Sabik JF, Gillinov AM, Blackstone EH, Vacha C, Houghtaling PL, Navia J, et al. Does off-pump coronary surgery reduce morbidity and mortality? J Thorac Cardiovasc Surg. 2002;124:698-707.

2. Puskas JD, Wright CE, Ronson RS, Brown WM 3rd, Gott JP, Guyton RA. Off-pump multivessel coronary bypass via sternotomy is safe and effective. Ann Thorac Surg. 1998;66:1068-72.

3. Koutlas TC, Elbeery JR, Williams JM, Moran JF, Francalancia NA, Chitwood WR Jr. Myocardial revascularization in the elderly using beating heart coronary artery bypass surgery. Ann Thorac Surg. 2000; 69:1042-7.

4. Yokoyama T, Baumgartner FJ, Gheissari A, Capouya ER, Panagiotides GP, Declusin RJ. Off-pump versus on-pump coronary bypass in high-risk subgroups. Ann Thorac Surg. 2000;70:1546-50.

5. Iaco AL, Contini M, Teodori G, Di Mauro M, Di Giammarco G, Vitolla G, et al. Off or on bypass: what is the safety threshold? Ann Thorac Surg. 1999;68:1486-9.

6. Calafiore AM, Teodori G, Di Giammarco G, Vitolla G, Maddestra N, Paloscia L, et al. Multiple arterial conduits without cardiopulmonary bypass: early angiographic results. Ann Thorac Surg. 1999;67:450-6.

7. Buffolo E, de Andrade CS, Branco JN, Teles CA, Aguiar LF, Gomes WJ. Coronary artery bypass grafting without cardiopulmonary bypass. Ann Thorac Surg. 1996;61:63-6.

8. Cleveland JC Jr, Shroyer AL, Chen AY, Peterson E, Grover FL. Off-pump coronary artery bypass grafting decreases risk-adjusted mortality and morbidity. Ann Thorac Surg. 2001;72:1282-8 (discussion 8-9).

9. Calafiore AM, Di Mauro M, Contini M, Di Giammarco G, Pano M, Vitolla G, et al. Myocardial revascularization with and without cardiopulmonary bypass in multivessel disease: impact of the strategy on early outcome. Ann Thorac Surg. 2001;72:456-62 (discussion 62-3).
10. Angelini GD, Taylor FC, Reeves BC, Ascione R. Early and midterm outcome after off-pump and on-pump surgery in Beating Heart Against Cardioplegic Arrest Studies (BHACAS 1 and 2): a pooled analysis of two randomised controlled trials. Lancet. 2002;359:1194-9.

11. Gundry SR, Romano MA, Shattuck OH, Razzouk AJ, Bailey LL. Seven-year follow-up of coronary artery bypasses performed with and without cardiopulmonary bypass. J Thorac Cardiovasc Surg. 1998; 115:1273-7 (discussion 7-8).

12. Arom KV, Flavin TF, Emery RW, Kshettry VR, Janey PA, Petersen RJ. Safety and efficacy of off-pump coronary artery bypass grafting. Ann Thorac Surg. 2000;69:704-10.

13. Puskas JD, Thourani VH, Marshall JJ, Dempsey SJ, Steiner MA, Sammons BH, et al. Clinical outcomes, angiographic patency, and resource utilization in 200 consecutive off-pump coronary bypass patients. Ann Thorac Surg. 2001;71:1477-83 (discussion 83-4).

14. Scott R, Blackstone EH, McCarthy PM, Lytle BW, Loop FD, White $\mathrm{JA}$, et al. Isolated bypass grafting of the left internal thoracic artery to the left anterior descending coronary artery: late consequences of incomplete revascularization. J Thorac Cardiovasc Surg. 2000;120: 173-84.

15. Bell MR, Gersh BJ, Schaff HV, Holmes DR Jr, Fisher LD, Alderman EL, et al. Effect of completeness of revascularization on long-term outcome of patients with three-vessel disease undergoing coronary artery bypass surgery. A report from the Coronary Artery Surgery Study (CASS) Registry. Circulation. 1992;86:446-57.

16. Jones EL, Weintraub WS. The importance of completeness of revascularization during long-term follow-up after coronary artery operations. J Thorac Cardiovasc Surg. 1996;112:227-37.

\section{Discussion}

Dr Robbin Cohen (Los Angeles, Calif). You report midterm results including 5-year follow-up of 406 off-pump bypass operations, which were compared with a group of propensity-matched pairs of the same size who underwent on-pump operations. I appreciated that you noted the fact that the perioperative results were originally reported at the 81 st annual meeting of The American Association for Thoracic Surgery and subsequently published in The Journal of Thoracic and Cardiovascular Surgery in 2002. It is important to note that in that report there were improvements in encephalopathy, sternal infections, blood use, and renal failure requiring dialysis. Unlike other reports at the same time, there was no difference between the off-pump and the on-pump groups in perioperative mortality, stroke, myocardial infarction, and reoperation for bleeding.

The current report gives some of the longest follow-up to date comparing on- with off-pump coronary surgery and shows the results in both groups to be excellent and equivalent. This is extremely important and reassuring in that it indicates that excellent long-term results can be obtained with off-pump coronary surgery when compared with the traditional model. At the same time, as a proponent of off-pump surgery, it is hard not to be at least a little disappointed that the results in the off-pump group weren't significantly better, and it bothers me that this seems to be something that is becoming more and more difficult to prove, at least more difficult to prove than we thought it would be. That is the basis for most of my questions.

In your study, fewer grafts per patient were performed in the off-pump group, which leads one to believe that many of the patients were incompletely revascularized, despite the fact that you showed very clearly that not only the severity but the extent of coronary disease seemed to be similar by statistical analysis. The only conclusion that I can make is that complete revascularization, 
something that we have held fairly dearly, is overrated. What do you think about that and how do your results explain that?

Dr Sabik. Thank you for your kind remarks. We were also concerned about the amount of incomplete revascularization in the off-pump patients, and this is one of the reasons we decided to do this study. Our expectations were that we would find more ischemic events in the off-pump patients and that these would be associated with incomplete revascularization. We were surprised when we did not find this. To examine incomplete revascularization more closely, I reviewed the operative notes of all patients who were incompletely revascularized and determined why this was so. We defined incomplete revascularization as lack of a bypass graft to any of the 3 coronary systems (LAD, circumflex, and right coronary artery) when there was a $50 \%$ or greater stenosis in that system, or when a patient had a $50 \%$ or greater left main stenosis and no bypass grafts to the LAD and circumflex. In reviewing the operative notes of the incompletely revascularized patients, I found that when the reason for incomplete revascularization was stated, such as the coronary was too small or the area was infarcted and scarred, the percentages in each group were similar. What differed was that in the off-pump group, there were more patients for whom no reason was given as to why an artery was grafted. I believe that in these cases, the surgeons' intention was not to bypass that artery, and therefore they felt it was not necessary to graft these arteries. Perhaps this is why we did not find incomplete revascularization to be associated with an increase in ischemic events.

Dr Cohen. This is a very elegant statistical analysis by 1 of our most respected statisticians, yet it is retrospective and the inclusion criterion for the study was basically surgeon preference. Have you done anything to determine which subgroups of patients in your analysis actually stand to gain the most by having their coronary operations performed off-pump? How has that affected the current indications for off-pump coronary bypass grafting at the Cleveland Clinic?

Dr Sabik. The problem with trying to answer that question is that there were too few events in this group of patients. In the 406 off-pump patients, there were only 2 deaths, 3 strokes, and 3 perioperative myocardial infarctions. To do a multivariable analysis and identify who benefits, we need many more events. At the Clinic, the decision to operate on- or off-pump still is based on surgeon preference. I can tell you my approach. I believe that morbidity is reduced by performing coronary surgery off-pump; so long as I can perform the same operation on- or off-pump, I perform off-pump surgery.

Dr Cohen. Finally, there have been considerable advances in technology and surgical technique since you undertook your original study, which was probably in the early to mid-1990s. All of these are designed to facilitate the conduct of the operation, such as proximal and distal anastomotic devices, endoscopic graft harvesting, a move toward arterial grafts. What do you think is the best off-pump coronary operation and why?

Dr Sabik. Let me answer that question in a few parts. I started this study in January of 1997 because that is when we obtained stabilizers and I believe reached a turning point in off-pump revascularization. Our techniques of exposure evolved over the period of the study. The best off-pump operation, I believe, is dependent on the patient. For a young patient, I prefer to use both internal thoracic arteries and use the right internal thoracic artery as a T-graft off of the left internal thoracic artery. This works well in off-pump surgery. The anterior and lateral walls of the left ventricle can be revascularized easily and with the best of conduits. What I use for the right coronary artery depends on the patient's age and degree of stenosis. If it is a moderate lesion, I would use a saphenous vein graft. In a young patient with a high-grade stenosis, I would use a gastroepiploic or radial artery.

Dr Cohen. Great. Again, I think this is incredibly important data and I really thank you for presenting it to us and also thanks for the opportunity to discuss it.

Dr Sabik. Thank you.

Dr Robert Reichman (Escondido, Calif). Earlier this year 1 of your coauthors, Dr Cosgrove, reported, in a brochure entitled "Surgical Outcomes of the Cleveland Clinic Hospitals," the incidence of off-pump CABG between 2000 and 2002 had decreased by $40 \%$. How do you account for this variation? In other words, a decrease in rate of off-pump coronary artery bypass at the clinic.

Dr Sabik. I think we did the greatest number of off-pump operations in 2001, between 350 and 400 cases, or about $30 \%$ of our primary coronary volume. As we have all observed, the number of primary coronary operations continues to decrease at the same time the complexity of primary coronary surgery is increasing. I think last year we did a little less than 300 off-pump operations, and I believe this was due to the combination of those 2 factors.

Dr Eugene Grossi (New York, NY). At the AATS last month we used propensity analysis to look at on- and off-pump patients and we balanced our propensity scores by looking at those factors that contribute to neurologic complications (ie, bad aortas, peripheral vascular disease, etc). In these high-risk patients, we showed advantages to the off-pump technique in terms of neurologic complications and mortality. I've always been intrigued because of the imbalance in the original model between peripheral vascular disease and previous stroke, which you published last year in this Journal. Have you had a chance to reanalyze your data or cull out and identify for us this high-risk patient subset, to determine if those patients will benefit from the OPCAB approach in your experience?

Dr Sabik. We have not done that, Gene. As I said earlier, it is impossible for us to identify a high-risk group because there have been so few events. There were only 3 strokes in the 406 off-pump patients. We need more patients and events to identify which patients benefit most from off-pump revascularization.

Steven R. Gundry (Palm Springs, Calif). I have a comment that confirms your observations. As you know, we reported a 7-year follow-up of actually matched patients from 1989 off-pump and on-pump, and we subsequently did a 10-year follow-up of those same patients. Surprisingly what we found was that, just like you, we did many fewer posterior desending artery and circumflex grafts in those days simply because in those days it was pretty dangerous, but despite that at 10 years the circumflex and the right distribution of the patients who were done off-pump were reintervened at the same rate as those who were done off-pump that had revascularization of that area. That was a striking finding at 10 days, that it really didn't make any difference in those areas, even 10 years later, that we didn't do them. I think you have found the same thing here. 
Dr Sabik. And some of that may be due to graft failure. At 10 years you would expect many of the vein grafts to start failing.

Dr Richard Anderson (Seattle, Wash). Just 1 quick question. I would never argue with Dr Blackstone and propensity analysis for case-matching. However, I always get a little bit nervous when in 1 of the primary sets there is a large extraction of patients at the outset and the reasons for that extraction are not transparent, so could you tell us, did you compare the 75 patients that you excluded because they didn't match with the patients that did match? And were there any important differences between those groups?

Dr Sabik. That is an excellent question, Dr Anderson. There are several ways to use propensity scoring. The method we used was a one-to-one match. This technique removed 75 of the offpump patients from the analysis. Other ways to use propensity scores are to (1) divide the patients into groups as determined by their propensity score, or (2) use the propensity score in a multivariable analysis. Dr Blackstone did the analysis using all 3 methods and essentially came up with the same conclusions. The method of one-to-one matching with propensity scores provided us with excellent matching. The 75 off-pump patients who were excluded from the analyhsis had different preoperative characteristics from the matched patients. They tended to be at extremes of age-very old or very young. They also tended to have either very good renal function or severe renal dysfunction, and they also tended to have less coronary artery disease. We were unable to find similar patients in the on-pump group, and that was due to our selection of these types of patients for off-pump surgery. Mortality was higher in the 75 unmatched off-pump patients. I believe it was $1.5 \%$ in the unmatched versus $0.5 \%$ in the matched off-pump patients. We believe the higher mortality in the unmatched patients was due to their higher risk characteristics. 